\title{
UMA AVALIAÇÃO QUANTITATIVA DA MEDIAÇÃO/CONCILIAÇÃO COMO PROCESSO PARA MELHORIA DA EFICIÊNCIA DO APARATO DO JUDICIÁRIO
}

\section{ARTIGO ORIGINAL}

MELO, Magaly Abreu de Andrade Palhares de ${ }^{1}$, MELO, Luis Alberto Martins Palhares $\mathrm{de}^{2}$, CALDAS, Camilo Onoda ${ }^{3}$

MELO, Magaly Abreu de Andrade Palhares de. MELO, Luis Alberto Martins Palhares de. CALDAS, Camilo Onoda. Uma avaliação quantitativa da mediação/conciliação como processo para melhoria da eficiência do aparato do judiciário. Revista Científica Multidisciplinar Núcleo do Conhecimento. Ano 06, Ed. 06, Vol. 17, pp. 129-155. Junho de 2021. ISSN: 2448-0959, Link de acesso: https://www.nucleodoconhecimento.com.br/lei/aparato-do-judiciario,

DOI: 10.32749/nucleodoconhecimento.com.br/lei/aparato-do-judiciario

\section{RESUMO}

O Poder Judiciário é um órgão demandado pela sociedade brasileira para resolução de conflitos das mais variadas naturezas e, por isso, apresenta considerável morosidade para finalizar os litígios. Uma forma de dar maior celeridade aos processos do Judiciário pode ser através dos procedimentos de mediação e conciliação, que se tornaram políticas públicas através dos ditames da Resolução 125/2010 do CNJ, do Novo Código de Processo Civil de 2015 e da Lei de Mediação (Lei № 13.140/2015). Este trabalho teve por objetivo avaliar e investigar a eficiência da mediação/conciliação com relação à resolução de conflitos de casos tratados na Justiça em primeira instância do TJSP, TJRJ e TJPI. Basicamente a avaliação feita

\footnotetext{
${ }^{1}$ Mestranda em Direito - Soluções alternativas de controvérsias empresariais pela Escola Paulista de Direito EPD, Pós-graduada em Métodos Adequados em Resolução de Conflitos pelo Instituto Brasiliense de Direito Público - IDP, Graduação em Direito pela Centro Universitário de Brasília - UniCEUB.

2 Doutor em Geografia pela UnB.

${ }^{3}$ Orientador. Doutorado em Direito.
}

RC: 90115

Disponível em: https://www.nucleodoconhecimento.com.br/lei/aparato-do-judiciario 
considerou estimativas da probabilidade de ocorrência de tempo de encerramento de processos tratados via mediação/conciliação e aplicou-se estes valores estimados a dados reais de processos tramitados (ou ainda em tramitação) na Justiça no período de 2013 a 2019, realizando assim uma simulação da abrangência do tempo de duração do processo até seu definitivo encerramento. Os resultados da simulação apontaram melhoria razoável da eficiência da resolução de conflitos, avaliados quantitativamente em termos da diminuição (1) do tempo até o encerramento do processo, (2) da carga de processos/magistrado/ano e (3) da carga de processos/servidor/ano. Como recomendação foi sugerido que se efetuem outros estudos para avaliação da eficiência via mediação/conciliação com outros dados (custas processuais, pessoal, instância judicial etc.) para melhor robustez da avaliação da mediação/conciliação.

Palavras-chave: Mediação, Conciliação, Eficiência do Judiciário, Celeridade de processos judiciais.

\section{INTRODUÇÃO}

O Poder Judiciário é um órgão extremamente demandado pela sociedade brasileira para gestão/resolução de conflitos das mais variadas naturezas: trabalhista, cível, consumerista, criminal, tributarista etc. Esta demanda exacerbada provoca um natural abarrotamento de processos com lentidão para julgá-los.

É notório o bordão popular que enuncia que "a justiça tarda, mas não falha". Isto sinaliza, de alguma forma, um estereótipo social referente à Justiça. Fica a imagem de que o trabalho do Poder Judiciário transcorre com morosidade.

De acordo com os argumentos trazidos por Rutckeviski (2002) a imagem de que a Justiça não acompanha a evolução de nossa era pode ser comprovada pela demora na resolução dos conflitos demandados. A falta de celeridade processual, portanto, é uma das maiores dificuldades enfrentadas na atualidade devido o arcabouço denso e arrastado do Poder Judiciário.

RC: 90115

Disponível em: https://www.nucleodoconhecimento.com.br/lei/aparato-do-judiciario 
Segundo Alvim (2003), a carência intrínseca na estrutura organizacional do Poder Judiciário é uma das culpadas pela vagarosidade dos julgamentos levados até ele.

E de fato, diversos autores fazem alusão à morosidade da Justiça. Por exemplo, Rutckeviski (2002) comenta que "a falta de celeridade processual, é uma das maiores dificuldades enfrentadas na atualidade devido o arcabouço denso e arrastado do Poder Judiciário". Alvim (2003) comenta sobre esta lentidão da Justiça considerando que "a carência intrínseca na estrutura organizacional do Poder Judiciário é uma das culpadas pela vagarosidade dos julgamentos levados até ele".

Desta forma, ações que visem dar maior celeridade ao processo judicial em si podem contribuir consideravelmente com sua eficiência. Neste contexto, os mecanismos adequados/alternativos de resolução de conflitos, mediação/conciliação/arbitragem, são sugestões viáveis para harmonizar e dar maior celeridade aos procedimentos promovendo como consequência o desafogamento do Poder Judiciário, por exemplo, como acontece com a mediação.

A Mediação e a Conciliação, apesar de serem consideradas como mecanismos contemporâneos e alternativos ao Judiciário, tem algumas de suas citações reportadas a época de Confúcio, mas, substancialmente tornou-se Política Pública através dos ditames da Resolução 125/2010 do CNJ, do Novo Código de Processo Civil de 2015 e da Lei de Mediação (Lei № 13.140/2015).

Como Política Pública tanto a mediação quanto a conciliação foram sendo demandadas e corroboraram com a implementação de Centros Judiciários de Solução de Conflitos - CEJUSC e conjunta e alinhadamente com o surgimento de estruturas extrajudiciais de apoio, como as Câmaras e Serventias Extrajudiciais, bem como pelo incentivo do trabalho de profissionais independentes, dos chamados mediadores ad hoc.

Desta forma, a mediação/conciliação pode ser uma alternativa para dar celeridade aos processos, proporcionando assim eficiência na resolução de conflitos/processos 
judiciais com relação ao tempo e alocação de recursos humanos utilizados para dissipação do contencioso judicial.

Este trabalho teve por objetivo investigar a eficiência da mediação/conciliação com relação à resolução de conflitos de casos tratados na Justiça em primeira instância. No escopo deste trabalho, a eficiência foi avaliada quantitativamente através quatro indicadores: (1) o tempo de duração do processo; (2) o índice do número de processos em tramitação por magistrado em determinado ano; (3) o índice do número de processos em tramitação por servidor atuante na área de 1ำ grau em determinado ano e (4) a taxa anual de encerramento de processos em tramitação.

Basicamente a avaliação feita neste trabalho foi considerar estimativas da probabilidade de ocorrência de tempo de encerramento de processos tratados via mediação/conciliação e aplicar estes valores estimados a dados reais de processos tramitados (ou ainda em tramitação) na Justiça no período de 2013 a 2019, realizando assim uma simulação da abrangência do tempo de duração do processo até seu definitivo encerramento. No que se segue são apresentados os procedimentos realizados.

\section{MATERIAIS E MÉTODOS}

Uma forma de se considerar a eficiência do funcionamento do aparato judicial é feita através da avaliação da celeridade do ciclo de vida dos processos que tramitam no âmbito da justiça para solucionar conflitos e, certamente, quanto menor o tempo do ciclo de vida do processo (até seu definitivo encerramento), melhor o desempenho do trabalho da esfera judicial, ou seja. melhor a eficácia e maior a eficiência deste trabalho. E a priori, o que se postula neste trabalho é o fato de que a mediação e/ou conciliação são processos que normalmente proporcionam menor tempo de ciclo de vida, se comparados aos processos de resolução pelas 'vias tradicionais' da Justiça.

RC: 90115

Disponível em: https://www.nucleodoconhecimento.com.br/lei/aparato-do-judiciario 
Para medir a eficiência da mediação/conciliação, foram escolhidos casos de primeira instância, pois já nesta fase o aparato judicial de alguma forma é acionado e, assim, é possível realizar a investigação sobre a eficiência do processo conciliatório.

Os dados básicos para elaboração deste trabalho são oriundos de duas fontes de dados: (1) dados de pesquisa de CNJ (2019) e (2) dados da série histórica de 2013 a 2019, disponível no síte do CNJ na Internet (CNJ, 2021). No que se segue são citados os dados destas fontes utilizados neste trabalho.

\section{OS DADOS DE CNJ (2019)}

Em CNJ (2019) foi realizado um estudo com o objetivo de "investigar o fluxo e a forma de gestão dos processos da Justiça Estadual de primeiro grau (comarcas e varas do interior e da capital), com relação à existência de conciliação e/ou mediação". (CNJ,2019, p.19). Na fase de obtenção de dados, os autores realizaram um procedimento de avaliação automatizada (mineração de texto) de documentos de decisões judiciais publicadas nos sites dos tribunais de justiça estaduais do Rio de Janeiro (TJRJ) e de São Paulo (TJSP) referentes aos processos inicializados e finalizados entre janeiro de 2013 e dezembro de 2017, e de documentos do tribunal de justiça do Piauí (TJPI) de processos de 2016 e 2017.

O processo de mineração de texto implementado pelos autores, em essência consistiu em aplicar buscas nos textos digitalizados:

a partir de alguma palavra-chave que identificasse a finalização dos processos após algum procedimento de conciliação ou mediação(...) assim, foram buscados os processos em que a expressão 'homologado' ou alguma de suas variações ('homologo') fosse encontrada (CNJ, 2019, p. 43).

Os autores fazem distinção entre "processos homologados" e "processos não homologados". Os autores ponderam que de acordo com o contexto da pesquisa,

considera-se que os processos finalizados por uma sentença homologatória passaram por algum tipo de mediação ou conciliação

RC: 90115

Disponível em: https://www.nucleodoconhecimento.com.br/lei/aparato-do-judiciario 
e, mesmo que o processo tenha ocorrido fora do judiciário (no escritório dos advogados, por exemplo), a máquina judicial foi movimentada e, portanto, teve algum papel no desfecho do processo (CNJ, 2019, p. 92).

Com base no processo de mineração de dados, os autores estimaram a percentagem de processos homologados e a percentagem de processos não homologados no TJPI, TJRJ e TJSP, onde um processo homologado, para os autores, é um processo que teve algum tipo de mediação/conciliação. Um dos procedimentos proporcionou a estimativa da taxa de processos homologados de processos sob a alçada do TJPI, TJRJ e TJPI. Para isso, os autores avaliaram processos de 91, 81 e 317 municípios do Piauí, Rio de Janeiro e São Paulo respectivamente. Os dados resumidos dos resultados obtidos estão apresentados na Tabela 1.

Tabela 1 - Taxa de processos homologados oriundos de processos de 91, 81 e 317 municípios do Piauí, Rio de Janeiro e São Paulo respectivamente

\begin{tabular}{|c|c|c|c|c|c|}
\hline UF & $\begin{array}{l}\text { Número de } \\
\text { municípios } \\
\text { avaliados }\end{array}$ & $\begin{array}{l}\text { Período } \\
\text { de } \\
\text { avaliação }\end{array}$ & $\begin{array}{l}\text { Processos } \\
\text { finalizados } \\
\text { avaliados }\end{array}$ & $\begin{array}{l}\text { Processos } \\
\text { homologados }\end{array}$ & $\begin{array}{l}\text { Processos } \\
\text { homologados } \\
\text { (\%) }\end{array}$ \\
\hline $\mathbf{P I}$ & 91 & $\begin{array}{l}2016 \quad e \\
2017\end{array}$ & 92.236 & 1.908 & $2,07 \%$ \\
\hline RJ & 81 & $\begin{array}{l}2013 \quad a \\
2017\end{array}$ & 11.554 .778 & 147.663 & $1,28 \%$ \\
\hline SP & 317 & $\begin{array}{ll}2013 & a \\
2017 & \end{array}$ & 9.635 .190 & 772.950 & $8,02 \%$ \\
\hline
\end{tabular}

Fonte: Elaborado pelos autores com base nas Tabelas 3, 9 e 12 de CNJ (2019).

Além disso, os autores também realizaram um trabalho para estimar o tempo de encerramento de processos homologados e não homologados. E são os dados

RC: 90115

Disponível em: https://www.nucleodoconhecimento.com.br/lei/aparato-do-judiciario 
deste trabalho que servem de base para, neste presente trabalho, utilizar as estimativas da probabilidade de ocorrência de tempo de encerramento de processos tratados via mediação/conciliação.

Para tal, os autores fizeram uma avaliação do tempo de duração dos processos (medido em dias) com base numa amostra de 256.056 processos de 17 municípios, sendo cinco piauienses, oito paulistas e quatro do Rio de Janeiro. No jargão estatístico, a variável estudada tempo de duração do processo é considerada uma variável aleatória. Designemos esta variável por $Y$. Os autores consideraram a variável $Y$ (tempo de duração) dos processos homologados e não homologados entre os 256.056 processos por unidade da federação (PI, RJ e SP) e elaboraram seis estimadores de função de probabilidade para a referida variável: (1) a distribuição de $Y$ para processos homologados no Piauí; (2) a distribuição de $Y$ para processos não homologados no Piauí; (3) a distribuição de $Y$ para processos homologados no Rio de Janeiro; (4) a distribuição de $Y$ para processos não homologados no Rio de Janeiro; (5) a distribuição de $Y$ para processos homologados em São Paulo e (6) a distribuição de $Y$ para processos não homologados em São Paulo.

Na Figura 21 em CNJ (2019, p. 101) os gráficos das seis distribuições de probabilidade de $Y$ estão apresentados e, neste trabalho, na Figura 1, a título de ilustração são apresentados os gráficos da distribuição de probabilidade de $Y$ para processos homologados e não homologados no estado do Piauí dos cinco municípios piauienses cujo tempo de duração foi averiguado.

Na Figura 1, os gráficos à esquerda acima e abaixo são imagens da Figura 21 (CNJ, 2019, p.101) e à direita acima e abaixo apresentam a função densidade da variável $\boldsymbol{Y}$ para processos homologados e não homologados do Piauí respectivamente, realçando as áreas de tempo de duração de um ano (0 a 365 dias), dois anos (366 a 730 dias), três anos (731 a 1095 dias), quatro anos (1096 a 1460 dias), cinco anos (1461 a 1825 dias) e seis anos ou mais (1826 em diante). Estes gráficos à direita 
estão destacando estes intervalos de 365 dias, pois eles foram usados no escopo do presente trabalho.

Figura 1 - Gráficos de distribuição de probabilidade da variável aleatória $\boldsymbol{Y}=$ tempo de duração do processo (medido em dias) para processos homologados e não homologados no estado do Piauí.
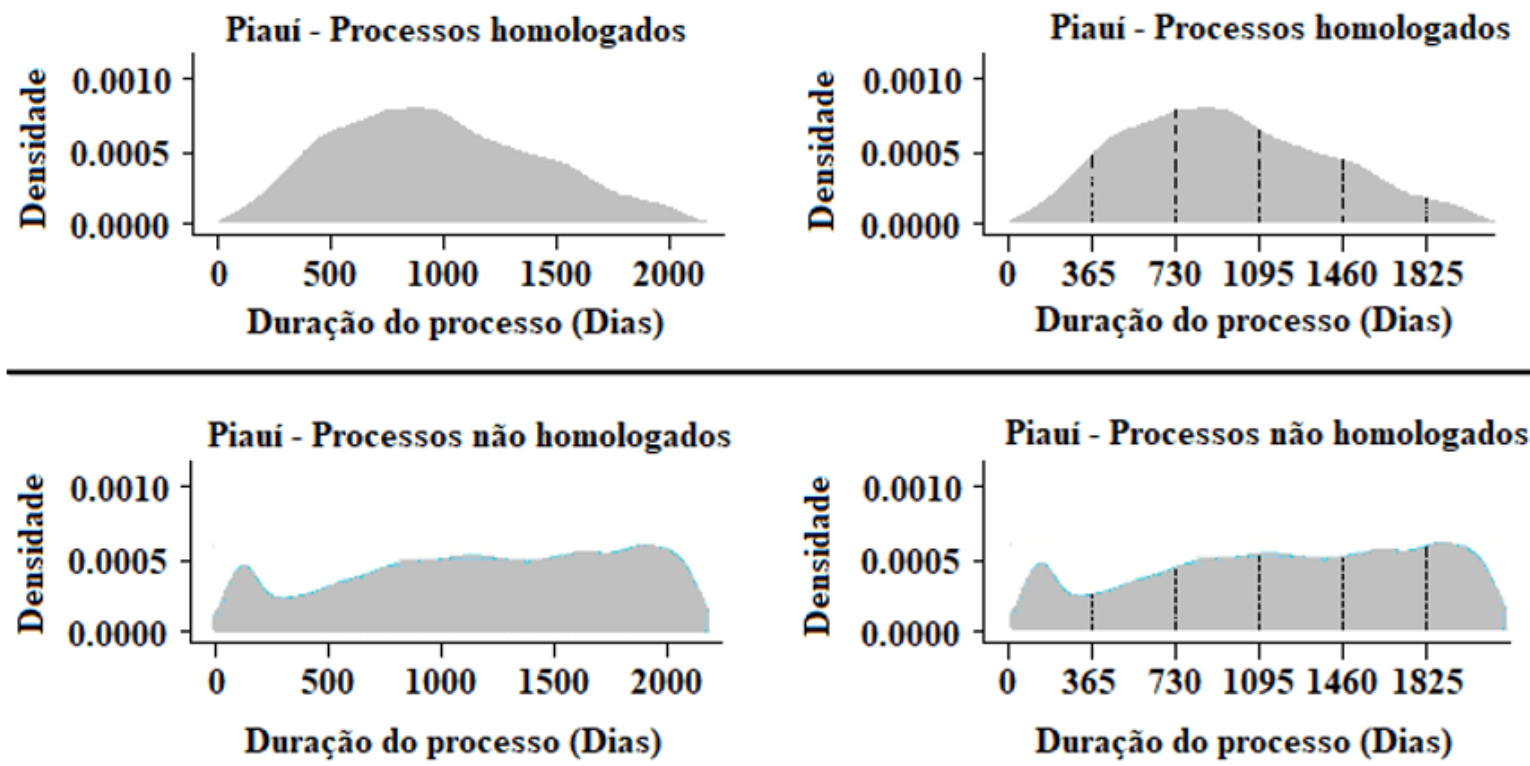

Fonte: elaborado pelos autores com base na Figura 21 de CNJ (2019, p. 101).

Com base na imagem destes gráficos, foram realizadas estimativas de probabilidade de $Y$ para intervalos de tempo de 365 dias. Na Tabela 2 estes valores estimados estão apresentados, ressaltando-se mais uma vez que são oriundos dos 256.056 processos considerados para avaliação do tempo de duração de cada processo.

Tabela 2 - Probabilidade de duração em anos dos 256.056 processos homologados e não homologados de 17 municípios do Piauí (5), Rio de Janeiro (4) e São Paulo (8)

\begin{tabular}{|l|l|l|l|l|l|l|l|}
\hline & & \multicolumn{7}{|c|}{ Probabilidade de encerrar o processo } \\
\hline UF & Encerramento & $1 \mathrm{a}$ & $366 \mathrm{a}$ & $731 \mathrm{a}$ & $1096 \mathrm{a}$ & $1461 \mathrm{a}$ & $\geq 1826$ \\
& & & & & & \\
\end{tabular}

RC: 90115

Disponível em: https://www.nucleodoconhecimento.com.br/lei/aparato-do-judiciario 


\begin{tabular}{|l|l|l|l|l|l|l|l|}
\hline & do processo & $\begin{array}{l}365 \\
\text { dias }\end{array}$ & $\begin{array}{l}730 \\
\text { dias }\end{array}$ & $\begin{array}{l}1095 \\
\text { dias }\end{array}$ & $\begin{array}{l}1460 \\
\text { dias }\end{array}$ & $\begin{array}{l}1825 \\
\text { dias }\end{array}$ & dias \\
$(1$ ano $)$ & $(2$ anos $)$ & $(3$ anos $)$ & $(4$ anos $)$ & $\begin{array}{l}(5 \text { anos }) \\
\text { anos })\end{array}$ \\
\hline PI & Homologado & 0,08378 & 0,26254 & 0,30370 & 0,20701 & 0,11349 & 0,02947 \\
\hline PI & $\begin{array}{l}\text { Não } \\
\text { homologado }\end{array}$ & 0,11031 & 0,12678 & 0,18942 & 0,19666 & 0,21338 & 0,16346 \\
\hline RJ & Homologado & 0,26445 & 0,31739 & 0,22030 & 0,12296 & 0,06782 & 0,00707 \\
\hline RJ & $\begin{array}{l}\text { Não } \\
\text { homologado }\end{array}$ & 0,25121 & 0,21401 & 0,16586 & 0,12153 & 0,11159 & 0,13580 \\
\hline SP & Homologado & 0,43516 & 0,32410 & 0,14317 & 0,06840 & 0,02476 & 0,00441 \\
\hline SP & Não & 0,19311 & 0,17613 & 0,15813 & 0,16624 & 0,14952 & 0,15687 \\
\hline & homologado & & & & & & \\
\hline
\end{tabular}

Fonte: elaborado pelos autores com base na Figura 21 de CNJ (2019, p. 101).

Com base na Tabela 2 é possível obter a estimativa da probabilidade de encerramento de determinado processo em intervalos de tempo de um ano. Por exemplo, a estimativa da probabilidade de um processo homologado no Rio de Janeiro terminar em três anos (entre 731 e 1095 dias) é:

$P(\boldsymbol{Y}=3)=0,22030=22,03 \%$.

No jargão estatístico, a variável aleatória é $\boldsymbol{Y}$ (duração em dias do processo) e agora estamos considerando esta variável medida em anos (intervalos de 365 dias). Assim, em (1) está se afirmando, no jargão estatístico, que a probabilidade de $\boldsymbol{Y}$ ser três anos (entre 731 e 1095 dias) é de 22,03\%.

Tomemos como outro exemplo a probabilidade de um processo não homologado em São Paulo terminar em quatro anos (entre 1096 e 1460 dias) seria escrita no jargão estatístico como apresentado em (2).

$\mathrm{P}(\boldsymbol{Y}=4)=0,16624=16,624 \% \approx 16,62 \%$.

RC: 90115

Disponível em: https://www.nucleodoconhecimento.com.br/lei/aparato-do-judiciario 
Em outras palavras, de acordo com a Tabela 2, podemos dizer que um processo de primeira instância em São Paulo que não for homologado tem 16,62\% de probabilidade de se encerrar em quatro anos (entre 1096 e 1460 dias). Supondo que em determinado dia ocorra o registro de $n=200$ casos novos de primeiro grau em São Paulo e que não serão homologados. Desta forma, destes $n=200$ casos, espera-se que $200 * 16,62 \%=33,24$ casos sejam resolvidos somente em quatro anos (entre 1096 e 1460 dias). No jargão estatístico diz que "o valor esperado (esperança) para $\boldsymbol{Y}=4$ é 33,24 casos" e escreve-se conforme (3).

$E(\boldsymbol{Y}=4)=200 * 16,62 \%=33,24$ casos.

São estes valores da Tabela 2 que são usados na simulação do presente trabalho como estimadores da probabilidade de encerramento em determinado tempo $t$, de um processo homologado ou não homologado em São Paulo, Rio de Janeiro e Piauí.

\section{OS DADOS DE CNJ (2021)}

A Base de Dados do CNJ (2021) dispõe de séries históricas diversas de diversos órgãos da Justiça, incluindo-se aí dados do TJPI, TJRJ e TJSP. Para que se calculem os indicadores deste presente trabalho, é necessário ter dados sobre o efetivo de magistrados e servidores dos tribunais e a citada base de dados dispõe desta série histórica.

Para o propósito deste trabalho foram acessados três variáveis da série histórica de 2013 a 2019 do TJRJ e TJSP e da série histórica de 2016 a 2019 para o TJPI. Estes períodos foram escolhidos pelo fato de Rio de Janeiro e São Paulo terem processos avaliados por CNJ (2019) de 2013 a 2017 e para o Piauí os processos avaliados foram de 2016 e 2017. As variáveis utilizadas estão apresentadas na Tabela 3.

RC: 90115

Disponível em: https://www.nucleodoconhecimento.com.br/lei/aparato-do-judiciario 
Tabela 3 - variáveis da série histórica de 2013 a 2019 de CNJ (2021) utilizadas

\begin{tabular}{|c|c|}
\hline $\begin{array}{l}\text { Código da variável } \\
\text { na } \\
\text { Base de Dados do } \\
\text { CNJ }\end{array}$ & Descrição da variável \\
\hline$c n 1$ & Casos novos de $1^{\circ}$ grau surgidos no ano \\
\hline mag & Total de magistrados disponíveis (atuantes) no ano \\
\hline sajud1 & $\begin{array}{l}\text { Total de servidores lotados na Área Judiciária do } 1^{0} \text { Grau } \\
\text { no ano }\end{array}$ \\
\hline
\end{tabular}

Fonte: elaborado pelos autores com base na Figura 21 de CNJ (2019, p. 101).

Com base nestas três variáveis coletadas nos anos de 2013 a 2019 e com base nos valores estimados de probabilidade de tempo de encerramento do ciclo de vida dos processos apresentados na Tabela 2 foram realizadas as simulações da dinâmica do tempo de encerramento dos processos.

\section{SIMULAÇÃO DA DINÂMICA DE TEMPO DE ENCERRAMENTO DE PROCESSOS}

As Tabelas 1 e 2 apresentam a taxa de processos homologados (e não homologados indiretamente) e a probabilidade de encerramento de um processo em um, dois, três, quatro, cinco e seis ou mais anos. Com esses dados é possível simular a dinâmica de tempo de encerramento dos processos que efetivamente foram casos novos de primeiro grau para o TJPI, TJRJ e TJSP, cujos valores estão disponíveis na Base de Dados do CNJ (2021).

Para avaliar a dinâmica de tempo de encerramento de processos, foram considerados apenas os dados reais de casos novos de 2013 a 2109 para o TJRJ e TJSP e apenas os casos novos de 2016 e 2017 do TJPI. Não foram computados,

RC: 90115

Disponível em: https://www.nucleodoconhecimento.com.br/lei/aparato-do-judiciario 
portanto, os processos iniciados antes de 2013 para o TJRJ e TJSP nem os processos iniciados antes de 2016 para o TJPI.

Assim, foram acessados os registros de casos novos de primeiro grau ocorridos nos anos de 2013 a 2019 no TJRJ e TJSP e os casos ocorridos de 2016 a 2019 no TJPI. Em seguida, foi calculada a estimativa de cada 'lote' de casos novos no ano, do percentual que teve encerramento 'homologado' (feito via mediação/conciliação) e encerramento 'não homologado' com base nos percentuais de homologação apresentados na Tabela 1. Em seguida, foi estimado o tempo de duração de cada processo homologado e não homologado, com base na Tabela 2, para cada um dos processos. Finalmente, foi calculada para cada ano, a estimativa de processos em tramitação do ano em questão. Para melhor entendimento, a seguir é apresentado o procedimento feito para os dados do TJSP. Tal procedimento foi o mesmo feito para o TJRJ e TJPI.

Inicialmente, para exemplificar, tomemos o resultado do número de casos novos de primeiro grau em 2013 do TJSP. Este dado é oriundo da variável cn1 citada na Tabela 3. Segundo CNJ (2021) foram $N=4.188 .012$ casos novos de primeiro grau em 2013. Com base na Tabela 1, em São Paulo estima-se que $8,02 \%$ dos casos sejam resolvidos com status 'homologado' e os demais sejam resolvidos com status 'não homologado'. Assim, considerando esta taxa, espera-se que dos 4.188.012 processos, ocorram $H=4.188 .012 * 8,02 \%=335.878,56 \approx 335.879$ casos homologados e $N H=N-H=4.188 .012-335.879=3.852 .133$ casos não homologados. $\mathrm{Na}$ Tabela 4 são apresentadas as estimativas para casos homologados $(H)$ e não homologados $(N H)$ dos casos novos de primeiro grau registrados no TJSP de 2013 a 2019.

Tabela 4 - Casos novos de primeiro grau dos anos de 2013 a 2019 do TJSP e valores esperados de casos homologados e não homologados dos mesmos
(A)
(B)
(C)

RC: 90115

Disponível em: https://www.nucleodoconhecimento.com.br/lei/aparato-do-judiciario 


\begin{tabular}{|l|l|l|l|}
\hline Ano & Casos novos & Processos homologados $(H)$ & Processos \\
\hline & de 1o grau $(N)$ & (Valor esperado: 8,02\%) & não homologados $(N H)$ \\
\hline $\mathbf{c n 1})$ & & & \\
\hline $\mathbf{2 0 1 3}$ & 4.188 .012 & 335.879 & \\
\hline $\mathbf{2 0 1 5}$ & 4.180 .691 & 335.291 & 3.852 .133 \\
\hline $\mathbf{2 0 1 6}$ & 3.624 .887 & 290.716 & 3.845 .400 \\
\hline $\mathbf{2 0 1 7}$ & 4.005 .941 & 321.276 & 2.947 .472 \\
\hline $\mathbf{2 0 1 8}$ & 3.843 .648 & 308.261 & 3.334 .171 \\
\hline $\mathbf{2 0 1 9}$ & 3.925 .116 & 314.794 & 3.684 .665 \\
\hline & & & 3.535 .387 \\
\hline
\end{tabular}

Obs.: (A) Dados obtidos de CNJ (2021) (B) Proporção de processos homologados no TJSP: 8,02\% (Ver Tabela 1) (C) Proporção de processos não homologados no TJSP: $91,98 \%$ (Ver Tabela 1) Fonte: elaborado pelos autores.

Em seguida, deseja-se estimar, para cada um dos casos novos de cada ano, em quanto tempo ele se encerrará. Para realizar esta estimativa foi usada a Tabela 2 onde se tem uma estimativa de encerramento de processo em um, dois, três, quatro, cinco e seis ou mais anos. Para exemplificar, considere os $N=4.188 .012$ casos novos de primeiro grau que entraram em 2013 no TJSP. Desses casos, espera-se que 335.879 sejam homologados e os demais 3.852 .133 sejam não homologados.

Assim, poderia ser estimado o número de processos homologados em São Paulo com encerramento em um ano (entre 1 e 365 dias), bastando multiplicar os $H=$ 335.879 casos novos (esperados) homologados pela probabilidade de encerramento em um ano que, como pode ser visto na Tabela 2 , vale $0,43516 \approx 43,52 \%$. Assim, dos 335.879 processos esperados serem resolvidos por homologação, espera-se 
que $335.879 * 43,52 \%=146.174,54 \approx 146.175$ casos sejam encerrados em um ano. E assim se procede para os demais valores de casos novos.

Contudo, neste trabalho optou-se por realizar sorteio para simular o tempo de encerramento de cada processo homologado e não homologado com base nos valores de probabilidade apresentados na Tabela 2. Foi utilizado o software estatístico R (2019) para realização dos sorteios, usando-se a função sample do referido software. Na Figura 2, a título de ilustração, é apresentado o código em linguagem $R$ usado para a amostragem dos $N=4.188 .012$ casos novos de primeiro grau em São Paulo em 2013 com término em um ano, dois anos e assim sucessivamente até seis ou mais anos.

RC: 90115

Disponível em: https://www.nucleodoconhecimento.com.br/lei/aparato-do-judiciario 
Figura 2 - Código em $\mathrm{R}$ para amostragem dos $N=4.188 .012$ casos novos de primeiro grau em São Paulo em 2013 com término em um ano, dois anos e assim sucessivamente até seis ou mais anos.

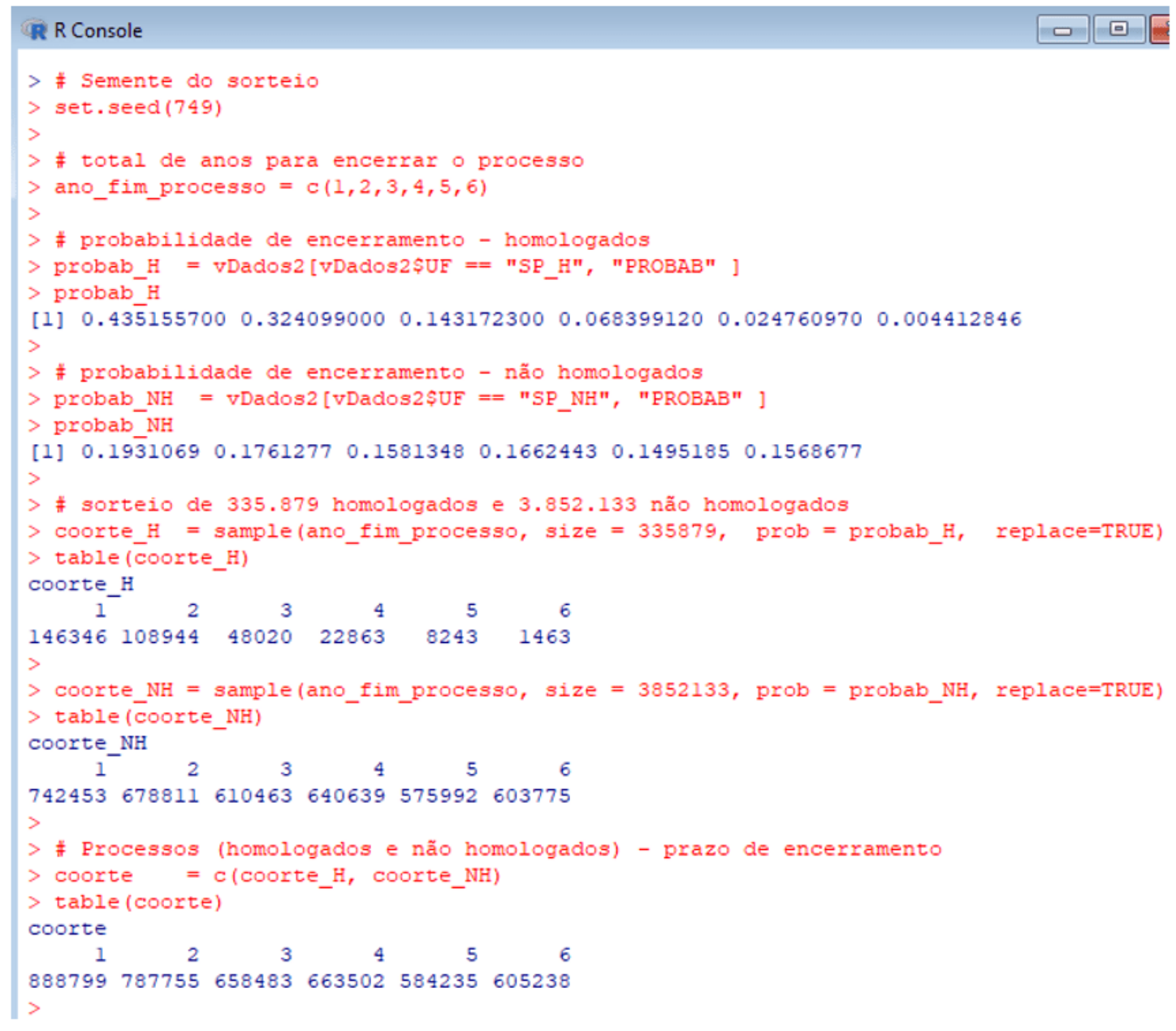

Fonte: elaborado pelos autores.

Conforme se observa na Figura 2, as variáveis do programa em $\mathrm{R}$ coorte_H e coorte_NH resumem a distribuição do término dos $N=4.188 .012$ processos. Por exemplo, espera-se que 22.863 dos 335.879 (esperados) processos homologados em São Paulo tenham encerramento em quatro anos (veja o valor na variável coorte_H do código R). E espera-se, por exemplo, que 603.775 dos 3.852 .133 processos não homologados se encerrem em seis ou mais anos (veja o valor na

RC: 90115

Disponível em: https://www.nucleodoconhecimento.com.br/lei/aparato-do-judiciario 
variável coorte_NH do código R). Para melhor ilustração, na Tabela 5 são apresentados estes valores gerados por sorteio no ambiente do software $\mathrm{R}$.

Tabela 5 - Distribuição dos $N=4.188 .012$ casos novos de primeiro grau em São Paulo em 2013 pelos valores esperados de processos homologados e não homologados com valores esperados de encerramento em um, dois, três, quatro, cinco ou seis ou mais anos

\begin{tabular}{|c|c|c|c|c|c|c|c|}
\hline Processo & $\begin{array}{l}1 \text { a } \\
365 \\
\text { dias } \\
\text { (1 ano) }\end{array}$ & $\begin{array}{l}366 \text { a } \\
730 \\
\text { dias } \\
(2 \\
\text { anos })\end{array}$ & $\begin{array}{l}731 \text { a } \\
1095 \\
\text { dias } \\
\text { (3 } \\
\text { anos) }\end{array}$ & $\begin{array}{l}1096 \text { a } \\
1460 \\
\text { dias } \\
(4 \\
\text { anos })\end{array}$ & $\begin{array}{l}1461 \text { a } \\
1825 \\
\text { dias } \\
(5 \\
\text { anos })\end{array}$ & $\begin{array}{l}\geq 1826 \\
\text { dias } \\
\text { ( } \geq \\
\text { anos) }\end{array}$ & Total \\
\hline SP - H & 146.346 & 108.944 & 48.020 & 22.863 & 8.243 & 1.463 & 335.879 \\
\hline SP - NH & 742.453 & 678.811 & 610.463 & 640.639 & 575.992 & 603.775 & 3.852 .133 \\
\hline SP - Total & 888.799 & 787.755 & 658.483 & 663.502 & 584.235 & 605.238 & 4.188 .012 \\
\hline
\end{tabular}

Fonte: elaborado pelos autores.

Da Tabela 5 temos que dos $N=4.188 .012$ casos novos de $2013,888.799$ (homologados e não homologados) se encerrarão no primeiro ano do processo (em 2013). Depois, no segundo ano, ocorrerá o encerramento de 787.755 processos (em 2014). E assim sucessivamente. Ressalta-se mais uma vez que estes são valores esperados obtidos com base na distribuição de probabilidade da variável aleatória $\boldsymbol{Y}$ (tempo de duração do processo) obtida do trabalho de CNJ (2019). Este procedimento de sorteio via código $\mathrm{R}$ foi realizado para todos os casos novos (cn1) de 2013 a 2019 para os processos do TJRJ e TJSP e casos novos (cn1) de 2016 a 2019 para os processos do TJPI.

RC: 90115

Disponível em: https://www.nucleodoconhecimento.com.br/lei/aparato-do-judiciario 
Para exemplificar, na Tabela 6 são apresentados o total esperado de casos encerrados (homologados ou não) em um, dois, três, quatro, cinco e seis ou mais anos para os casos novos de primeiro grau dos anos de 2013 a 2019 do TJSP.

Tabela 6 - Total esperado de casos encerrados (homologados ou não) em um, dois, três, quatro, cinco e seis ou mais anos para os casos novos de primeiro grau dos anos de 2013 a 2019 do TJSP.

\begin{tabular}{|c|c|c|c|c|c|c|c|}
\hline \multirow[b]{2}{*}{ Ano } & \multirow[b]{2}{*}{$\begin{array}{l}\text { Casos } \\
\text { novos } \\
1 \text { 1 grau }^{-} \\
\text {(cn1) }\end{array}$} & \multicolumn{6}{|c|}{$\begin{array}{l}\text { Valor esperado de casos encerrados (homologados ou } \\
\text { não) }\end{array}$} \\
\hline & & $\begin{array}{l}1 \mathrm{a} \\
365 \\
\text { dias } \\
\text { (1 ano) }\end{array}$ & $\begin{array}{l}366 \text { a } \\
730 \\
\text { dias } \\
\text { (2 anos) }\end{array}$ & $\begin{array}{l}731 \text { a } \\
1095 \\
\text { dias } \\
\text { (3 anos) }\end{array}$ & $\begin{array}{l}1096 \text { a } \\
1460 \\
\text { dias } \\
\text { (4 anos) }\end{array}$ & $\begin{array}{l}1461 \text { a } \\
1825 \\
\text { dias } \\
\text { (5 anos) }\end{array}$ & $\begin{array}{l}\geq 1826 \\
\text { dias } \\
(\geq \\
\text { anos) }\end{array}$ \\
\hline 2013 & 4.188 .012 & 888.799 & 787.755 & 658.483 & 663.502 & 584.235 & 605.238 \\
\hline 2014 & 4.180 .691 & 887.301 & 786.319 & 657.365 & 662.372 & 583.172 & 604.162 \\
\hline 2015 & 3.204 .471 & 680.326 & 602.709 & 503.557 & 507.519 & 447.275 & 463.085 \\
\hline 2016 & 3.624 .887 & 769.372 & 681.589 & 569.707 & 574.151 & 506.017 & 524.051 \\
\hline 2017 & 4.005 .941 & 850.145 & 753.420 & 629.885 & 634.495 & 559.051 & 578.945 \\
\hline 2018 & 3.843 .648 & 815.810 & 722.595 & 604.450 & 608.702 & 536.519 & 555.572 \\
\hline 2019 & 3.925 .116 & 832.942 & 737.991 & 617.214 & 621.685 & 547.975 & 567.309 \\
\hline
\end{tabular}

Fonte: elaborado pelos autores.

Com os valores esperados de tempo de encerramento de processos homologados e não homologados (em anos) é possível verificar o total de processos em tramitação ao longo dos anos e, assim, estimar os outros três indicadores de interesse neste

RC: 90115

Disponível em: https://www.nucleodoconhecimento.com.br/lei/aparato-do-judiciario 
trabalho: (1) o índice de processos por magistrado, (2) o índice de processos por servidor e (3) a taxa anual de encerramento de processos.

Contudo, não se tem a informação da data início e data de encerramento dos processos na base de dados do CNJ. Sabe-se apenas o ano em que os casos novos (cn1) se iniciaram. Assim, para facilitar o entendimento da simulação da dinâmica do tempo de encerramento dos processos e posteriormente calcular os indicadores de interesse, considerou-se que todos os casos novos de primeiro grau registrados ocorreram no primeiro dia do ano, ou seja, primeiro de janeiro. Inclusive foi por isso que foi escolhido o intervalo de 365 dias (um ano) para estimativa da probabilidade de encerramento do processo. Assim, se um processo iniciou em 2013 e tem encerramento esperado para um ano, este ano é o próprio ano de 2013 , independente do dia/mês em que foi iniciado, pois considera-se que ele iniciou em 01/01/2013.

Para visualização desta dinâmica de tempo de encerramento de processos foram construídos diagramas de Lexis para os dados do TJPI, TJRJ e TJSP. Para ilustração é apresentado na Figura 3 o diagrama de Lexis para os dados do TJSP.

RC: 90115

Disponível em: https://www.nucleodoconhecimento.com.br/lei/aparato-do-judiciario 
Figura 3 - Diagrama de Lexis da dinâmica de encerramento de processos de primeira instância do TJSP que se iniciaram entre 2013 e 2019.

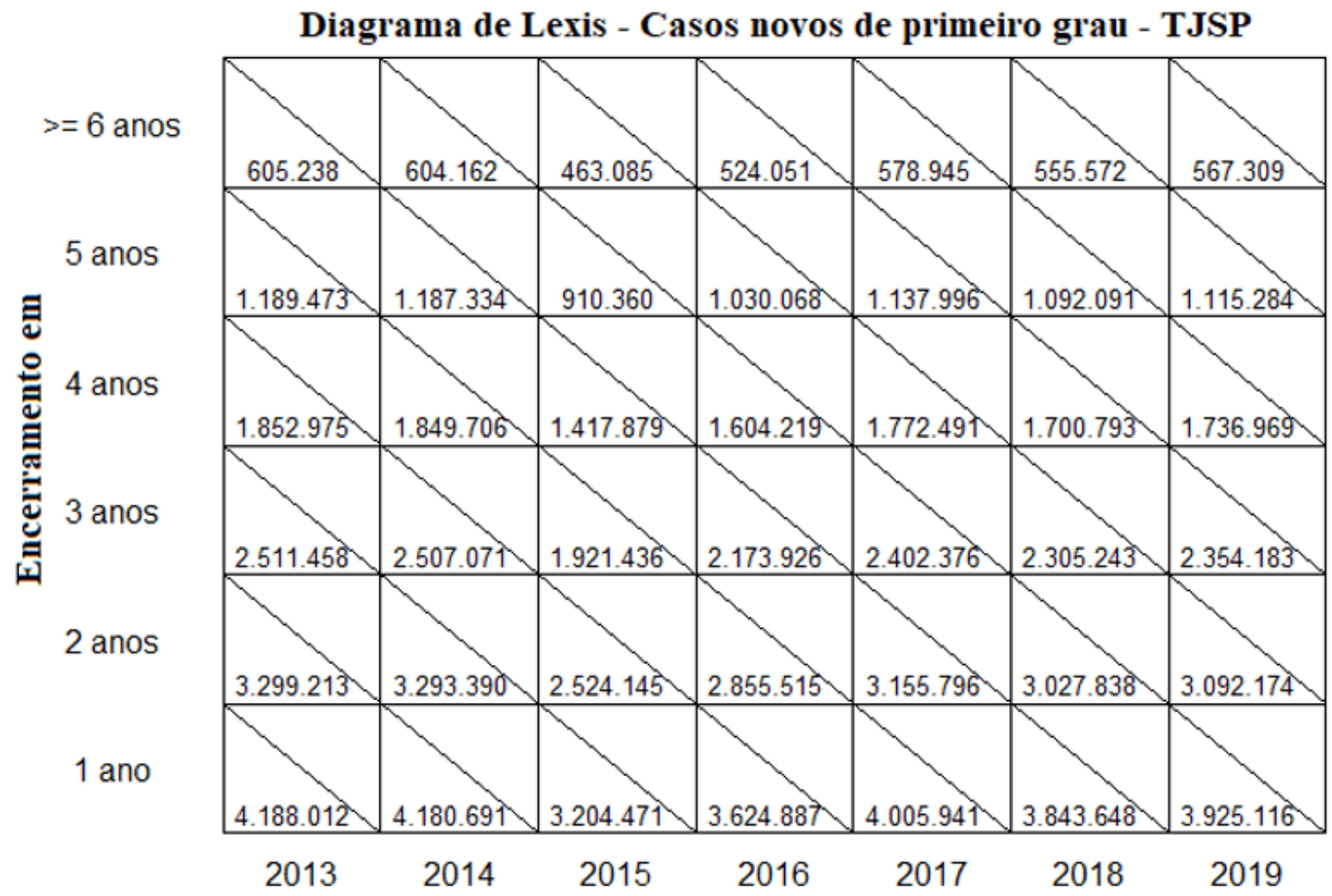

Fonte: elaborado pelos autores.

No diagrama de Lexis, a quantidade de processos 'ativos' em determinado ano está disposta nas colunas diagonais à esquerda tendo como base o ano em questão. Para exemplificar a construção e leitura do diagrama de Lexis seja o seguinte: Em 2013 foram registrados $N=4.188 .012$ casos novos que se iniciaram, por convenção, em 01/01/2013. Pela Tabela 6, 888.799 processos (homologados e não homologados) destes 4.188 .012 serão encerrados em um ano, ou seja, no mesmo ano que se iniciaram, em 2013. Mas a máquina judiciária foi acionada para todos os 4.188.012 processos. Assim, no diagrama de Lexis na coluna 2013 e linha 1 ano está registrado o valor de processos trabalhados pela Justiça, ou seja, 4.188.012.

Mas, para o segundo ano (em 2014), desses 4.188.012 processos devemos subtrair 888.799 que foram resolvidos em 2013. Assim, em 2014 restam 4.188.012 - 
$888.799=3.299 .213$ processos do 'lote' de 2013. Este valor está registrado na coluna 2013 linha 2 anos do diagrama de Lexis. Da Tabela 6 nota-se que o valor esperado de processos do lote de 2013 a ser encerrado com dois anos é 787.755. Assim, dos 3.299.213 processos do lote de 2013 em tramitação no segundo ano (em 2014) 787.755 serão encerrados. Daí, 3.299.213 $-787.755=2.511 .458$ processos do 'lote de 2013' seguirão no terceiro ano (em 2015). Este valor de 2.511 .458 está registrado na coluna 2013 linha 3 anos.

Procede-se assim ao preenchimento do diagrama de Lexis para cada coluna referente a determinado ano. A Tabela 6 dispõe de todos os valores necessários para preenchimento deste diagrama. Mais um exemplo: para preencher os valores do 'lote de 2018', nota-se na Tabela 6 que em 20183.843 .648 novos casos ocorreram. Este valor está registrado na coluna 2018 linha 1 ano. Já neste mesmo ano 815.810 foram encerrados. Assim, para o segundo ano do 'lote de 2018' (em 2019) sobram 3.843.648 $-815.810=3.027 .838$ processos e isso está registrado na coluna 2018 linha 2 anos. E desses 3.027 .838 processos que estão com 'dois anos de vida' 722.595 se encerrarão neste segundo ano. Assim sobrarão 3.027.838 $722.595=2.305 .243$ processos do 'lote de 2018' que seguem para seu terceiro ano (em 2020). Este registro está na coluna 2018 linha 3 anos.

Após o preenchimento das colunas ano a ano é possível então verificar a quantidade de processos em tramitação de determinado ano que, conforme dito, estão dispostos nas colunas diagonais à esquerda tendo como base o ano em questão. Para o ano de 2013 tem-se o total de 4.188 .012 processos que ocuparam em alguma instância a máquina do judiciário. Em 2014 ocorreu a entrada de 4.180.691 casos novos como se observa na Tabela 6. Mas, adicionalmente, ainda há o remanescente de 3.299.213 processos do 'lote de 2013'. Então na diagonal à esquerda de 2014 no diagrama de Lexis temos registrado 4.180 .691 (coluna 2014 linha 1 ano) +3.299 .213 (coluna 2013 linha 2 anos) $=7.479 .904$ processos (de primeiro grau) em tramitação no TJSP em 2014.

RC: 90115

Disponível em: https://www.nucleodoconhecimento.com.br/lei/aparato-do-judiciario 
Em 2018, por exemplo, temos 12.383 .821 processos de $1^{\circ}$ grau que ocupam o judiciário de alguma forma assim distribuídos: 3.843 .648 casos novos de 2018 (coluna 2018 linha 1 ano) +3.155 .796 processos de 2 anos de 2017 (coluna 2017 linha 2 anos) + 2.173.926 processos de 3 anos de 2016 (coluna 2016 linha 3 anos) + 1.417.879 processos de 4 anos de 2015 (coluna 2015 linha 4 anos) + 1.187.334 processos de 5 anos de 2014 (coluna 2014 linha 5 anos) +605.238 processos de 6 anos (ou mais) de 2013 (coluna 2013 linha >= 6 anos).

Desta forma obtém-se uma estimativa razoável do volume de processos a cada ano e daí é possível calcular os indicadores usados neste trabalho, resultantes da simulação.

\section{INDICADORES - ÍNDICE DE PROCESSOS POR MAGISTRADO E POR SERVIDORES POR ANO}

Uma vez que se tem uma estimativa do volume de processos em tramitação ao longo dos anos e se tem os dados (reais) das variáveis mag e sajud1 (ver Tabela 3), é simples o cálculo do índice de processos de primeiro grau por magistrados e/ou por servidores ao longo dos anos. Por exemplo, segundo a base de dados do CNJ (2021), em 2013 o TJSP tinha 2.501 magistrados e em 2014 havia 2.566 magistrados em atividade, não só para casos de primeiro grau, mas para demais instâncias.

Ainda assim, uma estatística razoável que ajuda a medir a eficiência da justiça seria o valor da razão de processos por magistrado. Então, em São Paulo em 2013 teríamos um índice de 4.188.012 / $2.501=1.674,74$ processos $/$ magistrado e em 2014 este índice é de $(3.299 .213+4.180 .691) / 2.566=7.479 .904 / 2.566=$ $2.915,01$ processos/magistrado. Um aumento de $74 \%$ na carga de processos por magistrado de 2013 para 2014. E vale observar novamente que consideramos apenas a distribuição dos processos de primeiro grau por todos os magistrados e, neste cálculo, não estão computados os processos anteriores a 2013 o que faria certamente aumentar este índice.

RC: 90115

Disponível em: https://www.nucleodoconhecimento.com.br/lei/aparato-do-judiciario 
As razões por magistrado e por servidor foram calculadas para os anos de 2013 a 2019 para o TJRJ e TJSP. Para o TJPI, para os anos de 2016 a 2019. Para exemplificar, na Tabela 7 são apresentados os valores dos índices para magistrados e servidores para os dados do TJSP.

Tabela 7 - Número de processos por magistrado e por servidores dos lotes de casos novos de primeiro grau (cn1) de 2013 a 2019 no TJSP

\begin{tabular}{|c|c|c|c|c|c|}
\hline Ano & \begin{tabular}{|l} 
Total de \\
Processos \\
em \\
tramitação
\end{tabular} & $\begin{array}{l}\text { Total de } \\
\text { Magistrados } \\
\text { (mag) }\end{array}$ & $\begin{array}{l}\text { Índice } \\
\text { processos } \\
\text { por } \\
\text { Magistrado }\end{array}$ & $\begin{array}{l}\text { Total de } \\
\text { Servidores } \\
\left(1^{\circ} \mathrm{grau}\right) \\
\text { (sejud1) }\end{array}$ & $\begin{array}{l}\text { Índice } \\
\text { processos } \\
\text { por } \\
\text { servidor }\end{array}$ \\
\hline 2013 & 4.188 .012 & 2.501 & 1674,53 & 39.411 & 106,27 \\
\hline 2014 & 7.479.904 & 2.566 & 2915,01 & 41.173 & 181,67 \\
\hline 2015 & 9.009 .319 & 2.335 & 3858,38 & 35.335 & 254,97 \\
\hline 2016 & 10.509 .078 & 2.397 & 4384,26 & 35.973 & 292,14 \\
\hline 2017 & 11.822 .071 & 2.519 & 4693,16 & 35.004 & 337,73 \\
\hline 2018 & 12.383.821 & 2.581 & 4798,07 & 35.005 & 353,77 \\
\hline 2019 & 12.474.071 & 2.503 & 4983,65 & 34.060 & 366,24 \\
\hline
\end{tabular}

Fonte: elaborado pelos autores.

\section{INDICADOR - TAXA DE PROCESSOS ENCERRADOS NO ANO}

Outro indicador que pode sinalizar a eficiência da mediação/conciliação é a taxa de processos encerrados $(E)$ no ano em relação a todos os processos em tramitação no ano $(T)$. É o resultado da divisão E/T podendo variar entre zero e um. Quanto mais próximo da unidade, isto sinaliza que mais processos foram encerrados no ano. Se a

RC: 90115

Disponível em: https://www.nucleodoconhecimento.com.br/lei/aparato-do-judiciario 
taxa for a unidade, significa que todos os processos em tramitação no ano se encerraram neste mesmo ano.

Para exemplificar, na Tabela 8 são apresentados os valores das taxas de processos encerrados nos anos de 2013 a 2019 decorrentes da simulação de encerramento dos processos do TJSP.

Tabela 8 - Taxa de encerramento de processos no ano - TJSP

\begin{tabular}{|c|c|c|c|}
\hline Ano & $\begin{array}{l}\text { Processos } \\
\text { Encerrados } \\
\text { (E) }\end{array}$ & $\begin{array}{l}\text { Processos em } \\
\text { tramitação } \\
\text { (T) }\end{array}$ & $\begin{array}{l}\text { Taxa de } \\
\text { encerramento } \\
(\mathrm{E} / \mathrm{T})\end{array}$ \\
\hline 2013 & 888.799 & 4.188 .012 & 0,2122 \\
\hline 2014 & 1.675 .056 & 7.479 .904 & 0,2239 \\
\hline 2015 & 2.125 .128 & 9.009 .319 & 0,2359 \\
\hline 2016 & 2.692 .948 & 10.509 .078 & 0,2562 \\
\hline 2017 & 3.281 .898 & 11.822 .071 & 0,2776 \\
\hline 2018 & 3.834 .866 & 12.383 .821 & 0,3097 \\
\hline 2019 & 3.811 .010 & 12.474 .071 & 0,3055 \\
\hline
\end{tabular}

Obs.: os processos encerrados (E) são valores esperados de encerramento (ver Tabela 6) Fonte: elaborado pelos autores.

\section{EFICIÊNCIA VIA MEDIAÇÃO/CONCILIAÇÃO}

Os procedimentos feitos com os dados do TJSP, TJRJ e TJPI e que foram exemplificados acima com os dados do TJSP para se obter indicadores de aferição da eficiência da mediação/conciliação se baseiam na estimativa do percentual de processos homologados (com alguma solução via mediação/conciliação) de 8,02\%, $1,27 \%$ e $2,07 \%$ para os processos de primeira instância da alçada do TJSP, TJRJ e TJPI respectivamente.

RC: 90115

Disponível em: https://www.nucleodoconhecimento.com.br/lei/aparato-do-judiciario 
O objetivo deste trabalho é investigar se a mediação/conciliação pode proporcionar maior celeridade aos processos, contribuindo com maior eficiência do judiciário. Supondo que na alçada do TJSP, TJRJ e TJPI sejam feitos esforços para que se aumentem a resolução dos conflitos pela via da mediação/conciliação, foi realizada simulação com os dados de 2013 a 2019 do CNJ supondo que os três tribunais conseguissem uma taxa de $25 \%$ de mediação/conciliação e depois foi realizada outra simulação com uma taxa de $50 \%$. Para este procedimento foi mantida a probabilidade de resolução dos processos homologados conforme discriminado na Tabela 2.

Os resultados destas simulações, para os dados dos três tribunais estão apresentados nas Figuras 4 a 9 abaixo.

Figura 4 - Simulações dos valores dos indicadores (a) processos/magistrado/ano e (b) processos/servidores/ano os dados do TJSP.
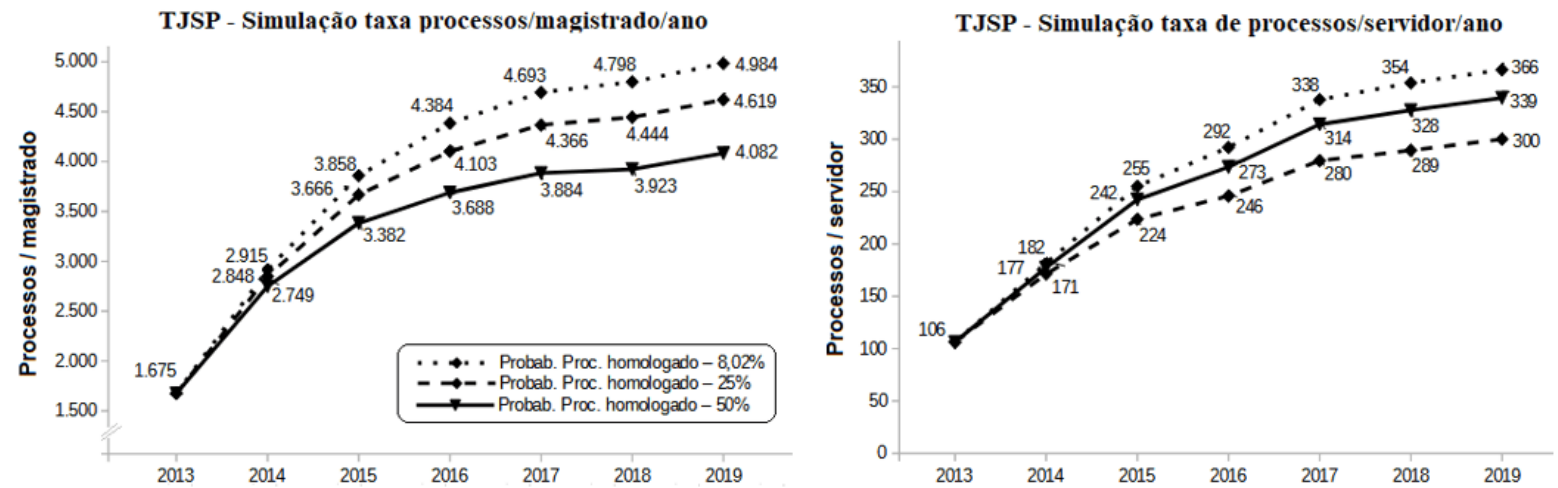

Fonte: elaborado pelos autores com base na Figura 21 de CNJ (2019, p. 101).

Para o índice de processos/magistrado com os dados do TJSP observa-se na Figura 4 um valor esperado de 1.675 processos/magistrado em 2013. Em 2015 considerando a taxa de homologação de 8,02\% seria esperada um índice de 3.858 processos/magistrado (considerando o legado de processos remanescentes de 2013, de 2014 e os novos de 2015). Pela simulação, se a taxa de homologação fosse de $25 \%$, este índice cairia para 3.666 processos/magistrado. Isto representa $3.858-3.666=192$ processos a menos por magistrado que representa $192 / 3.858$

RC: 90115

Disponível em: https://www.nucleodoconhecimento.com.br/lei/aparato-do-judiciario 
$=4,98 \%$ a menos de processos para cada magistrado no período de dois anos (2013 a 2015). E pela simulação, se a taxa de homologação fosse de $50 \%$, este índice cairia para 3.382 processos/magistrado. Isto representa $3.858-3.382=476$ processos a menos por magistrado, ou seja, $476 / 3.858=12,34 \%$ a menos de processos para cada magistrado no período de dois anos (2013 a 2015).

Deve-se levar em conta que o índice de processos/magistrado depende do número de casos novos e do número de magistrados alocados no Tribunal. Se em determinado ano os números de casos forem muito maiores que os casos novos dos anos anteriores e o número de magistrados for mantido ou mesmo reduzido, o índice de processos/magistrado naturalmente aumentará. Mas estas situações são independentes do processo de mediação/conciliação.

De qualquer forma, conforme a Figura 4, supondo que no período de 2013 a 2019 a proporção de processos homologados fosse $25 \%$ (provavelmente uma meta mais facilmente alcançável se comparada à proporção de 50\%) em 2019 seria esperada uma carga de 4.619 processos/magistrado, ao passo que se a proporção de processos homologados fosse os atuais $8,02 \%$ estimados, em 2019 seria esperada uma carga de 4.984 processos/magistrado. Isto significa que a taxa de processos homologados de $25 \%$ acarretaria uma redução de $4.984-4.619=365$ processos, ou seja, $365 / 4.984=7,32 \%$ de processos a menos para cada magistrado. $\mathrm{Da}$ mesma forma, a carga de processos por servidor em 2019 apresentaria uma redução de $366-300=66$ processos, ou seja, $66 / 366=18,03 \%$ processos a menos para cada servidor.

Isto certamente contribuiria para melhorar a qualidade do trabalho do magistrado e do servidor, contribuindo para a melhoria geral do funcionamento aparato judiciário, ou seja, melhorando a eficiência do trabalho da Justiça.

RC: 90115

Disponível em: https://www.nucleodoconhecimento.com.br/lei/aparato-do-judiciario 
Figura 5 - Simulações dos valores dos indicadores (a) processos/magistrado/ano e (b) processos/servidores/ano os dados do TJRJ.
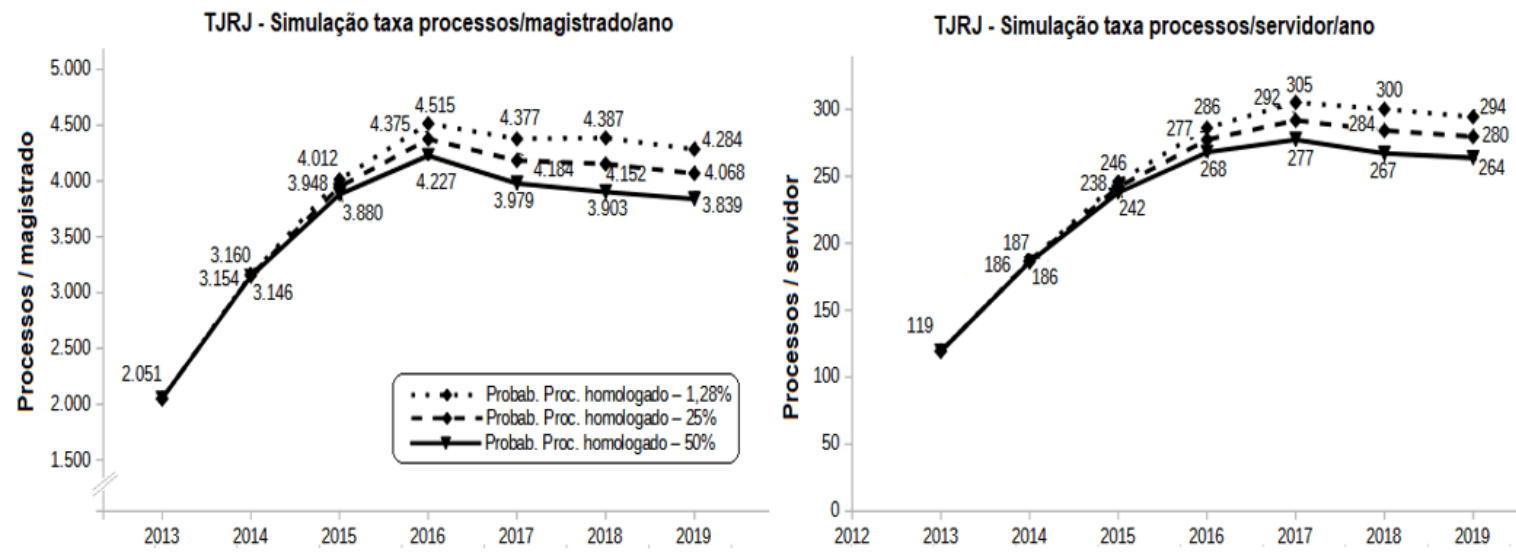

Fonte: elaborado pelos autores.

Para o índice de processos/magistrado com os dados do TJRJ observa-se na Figura 5 um valor esperado de 2.051 processos/magistrado em 2013. Em 2016 considerando a taxa de homologação de 1,28\% (valor estimado para o Rio de Janeiro - veja Tabela 1) seria esperada um índice de 4.515 processos/magistrado (considerando o legado de processos remanescentes de 2013, de 2014, de 2015 e os novos de 2016). Pela simulação, se a taxa de homologação fosse de $25 \%$, este índice cairia para 4.375 processos/magistrado. Isto representa $4.515-4.375=140$ processos a menos por magistrado que representa $140 / 4.515=3,10 \%$ a menos de processos para cada magistrado no período de três anos (2013 a 2016). E pela simulação, se a taxa de homologação fosse de $50 \%$, este índice cairia para 4.227 processos/magistrado. Isto representa $4.515-4.227=288$ processos a menos por magistrado, ou seja, $288 / 4.515=6,38 \%$ a menos de processos para cada magistrado no período de três anos (2013 a 2016).

Supondo que no período de 2013 a 2019 a proporção de processos homologados fosse $25 \%$ (provavelmente uma meta mais facilmente alcançável se comparada à proporção de 50\%) em 2019 seria esperada uma carga de 4.068 processos/magistrado, ao passo que se a proporção de processos homologados 
fosse os atuais 1,28\% estimados, em 2019 seria esperada uma carga de 4.284 processos/magistrado. Isto significa que a taxa de processos homologados de $25 \%$ acarretaria uma redução de $4.284-4.068=216$ processos, ou seja, $216 / 4.284=$ $5,04 \%$ de processos a menos para cada magistrado. Da mesma forma, a carga de processos por servidor em 2019 apresentaria uma redução de $294-280=14$ processos, ou seja, 14 / $294=4,76 \%$ processos a menos para cada servidor.

Figura 6 - Simulações dos valores dos indicadores (a) processos/magistrado/ano e (b) processos/servidores/ano os dados do TJPI.
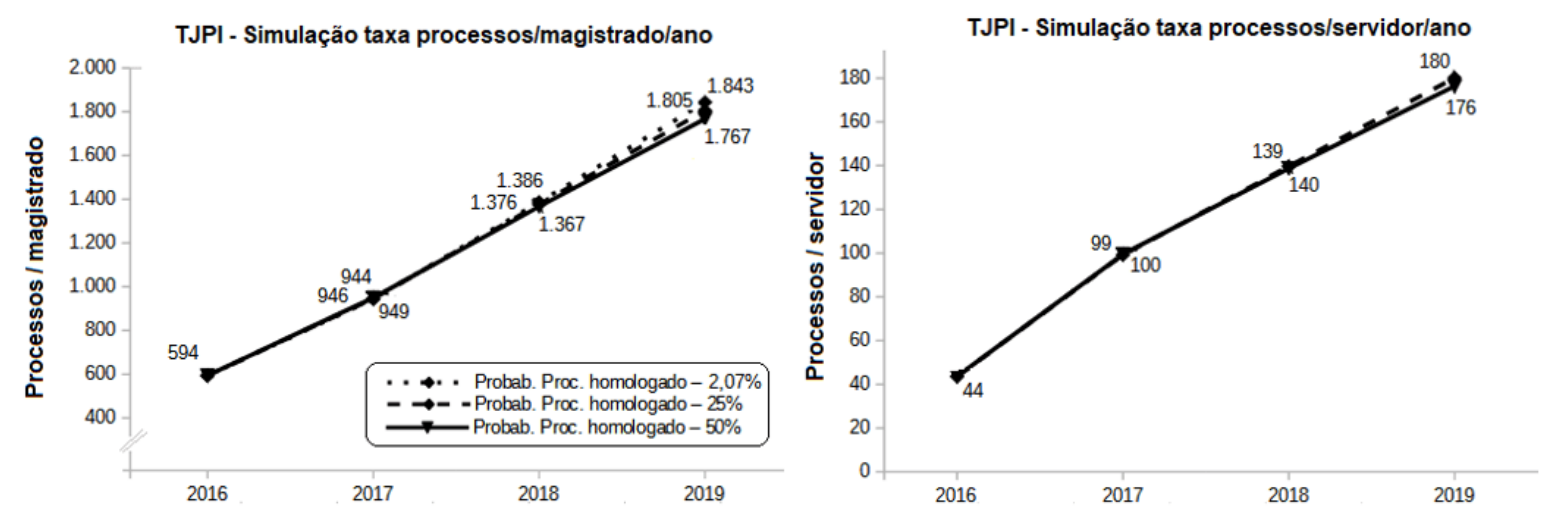

Fonte: elaborado pelos autores.

Os resultados da simulação para os dados do Piauí estão apresentados na Figura 6 e o que se verifica é que com o processo de homologação na proporção de $25 \%$ obtém-se no período de três anos (2016 a 2019) uma redução de $1843-1805=38$ processos/magistrado o que corresponde a uma redução de $38 / 1805=2,06 \%$ a menos de processos para cada magistrado no período de três anos (2016 a 2019). Redução similar se obtém para os servidores, pois em 2019 teríamos $180-176=4$ processos a menos para cada servidor o que representa $4 / 180=2,22 \%$ a menos da carga de trabalho.

RC: 90115

Disponível em: https://www.nucleodoconhecimento.com.br/lei/aparato-do-judiciario 
Figura 7 - Simulações dos valores das taxas de encerramento dos processos no ano para o TJSP.

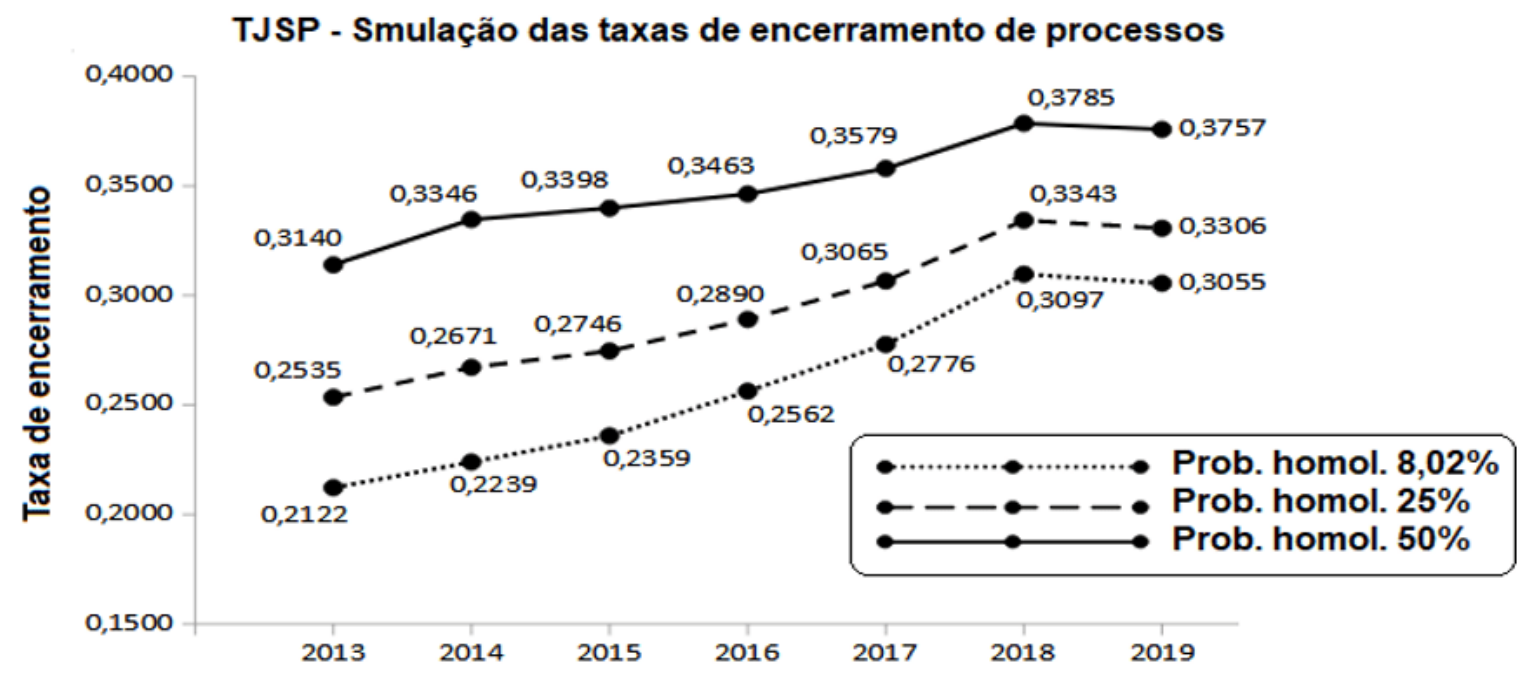

Fonte: elaborado pelos autores.

$\mathrm{Na}$ Figura 7, para o TJSP, considerando a proporção de $25 \%$ para processos homologados, espera-se uma taxa de encerramento anual em média $3 \%$ maior se comparada com a atual taxa de homologação (8,02\% da amostra de dados). Em 2019, por exemplo, a taxa de encerramento é de 33,06\% para a proporção de $25 \%$ de homologação enquanto esta mesma taxa é de $30,55 \%$ se a proporção de homologação for de 8,02\%. Isto significa dizer que, em 2019, em um lote de 100 processos, seria esperado que 33,06 fossem encerrados com a proporção de homologação de $25 \%$. Mas se a proporção de homologação fosse $8,02 \%$ seria esperado o encerramento de 30,55 processos, aproximadamente três processos a menos portanto.

RC: 90115

Disponível em: https://www.nucleodoconhecimento.com.br/lei/aparato-do-judiciario 
Figura 8 - Simulações dos valores das taxas de encerramento dos processos no ano para o TJRJ.

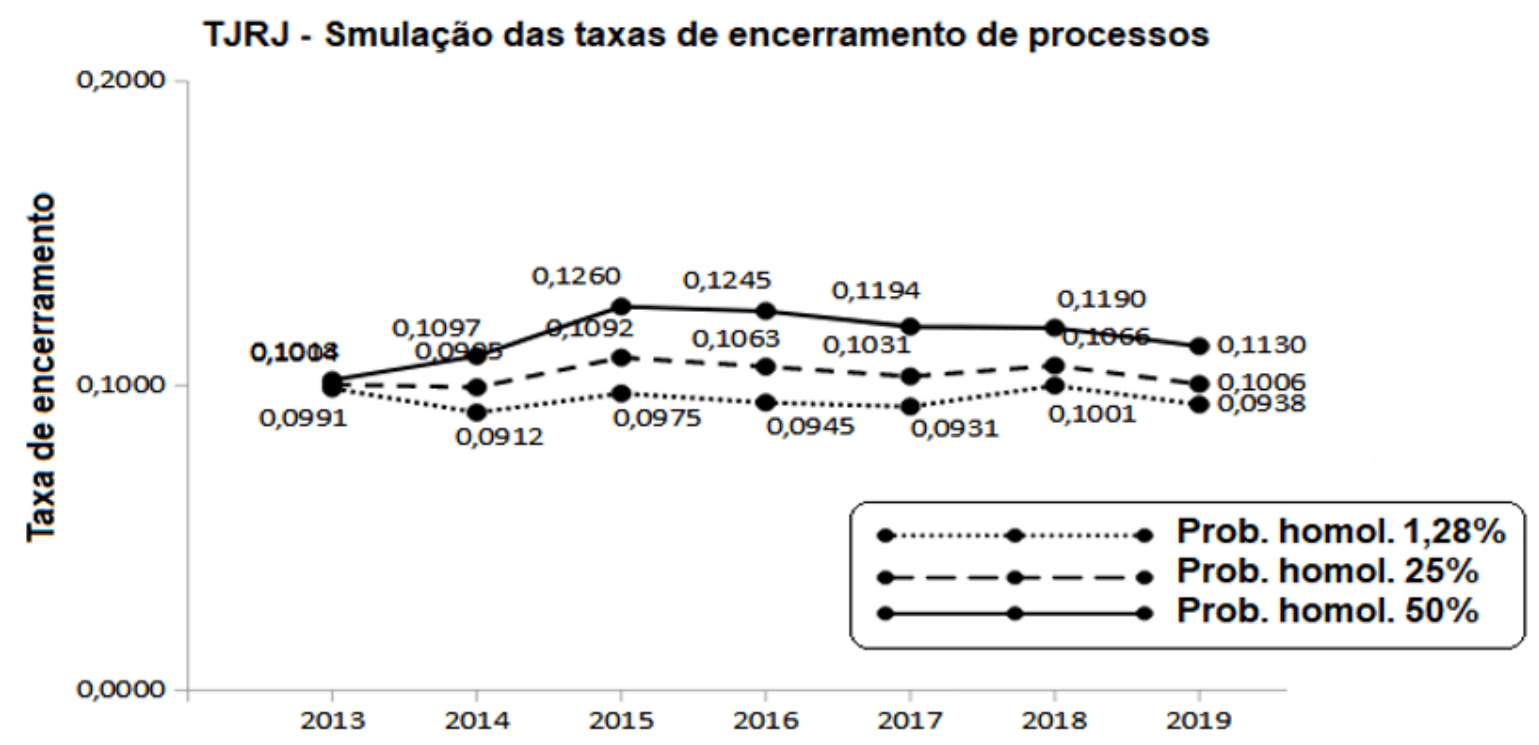

Fonte: elaborado pelos autores.

Para os dados do TJRJ, pode-se dizer que a taxa de encerramento basicamente se mantém inalterada, mantendo a diferença de um processo, se a proporção de homologação for de $25 \%$.

RC: 90115

Disponível em: https://www.nucleodoconhecimento.com.br/lei/aparato-do-judiciario 
Figura 9 - Simulações dos valores das taxas de encerramento dos processos no ano para o TJPI.

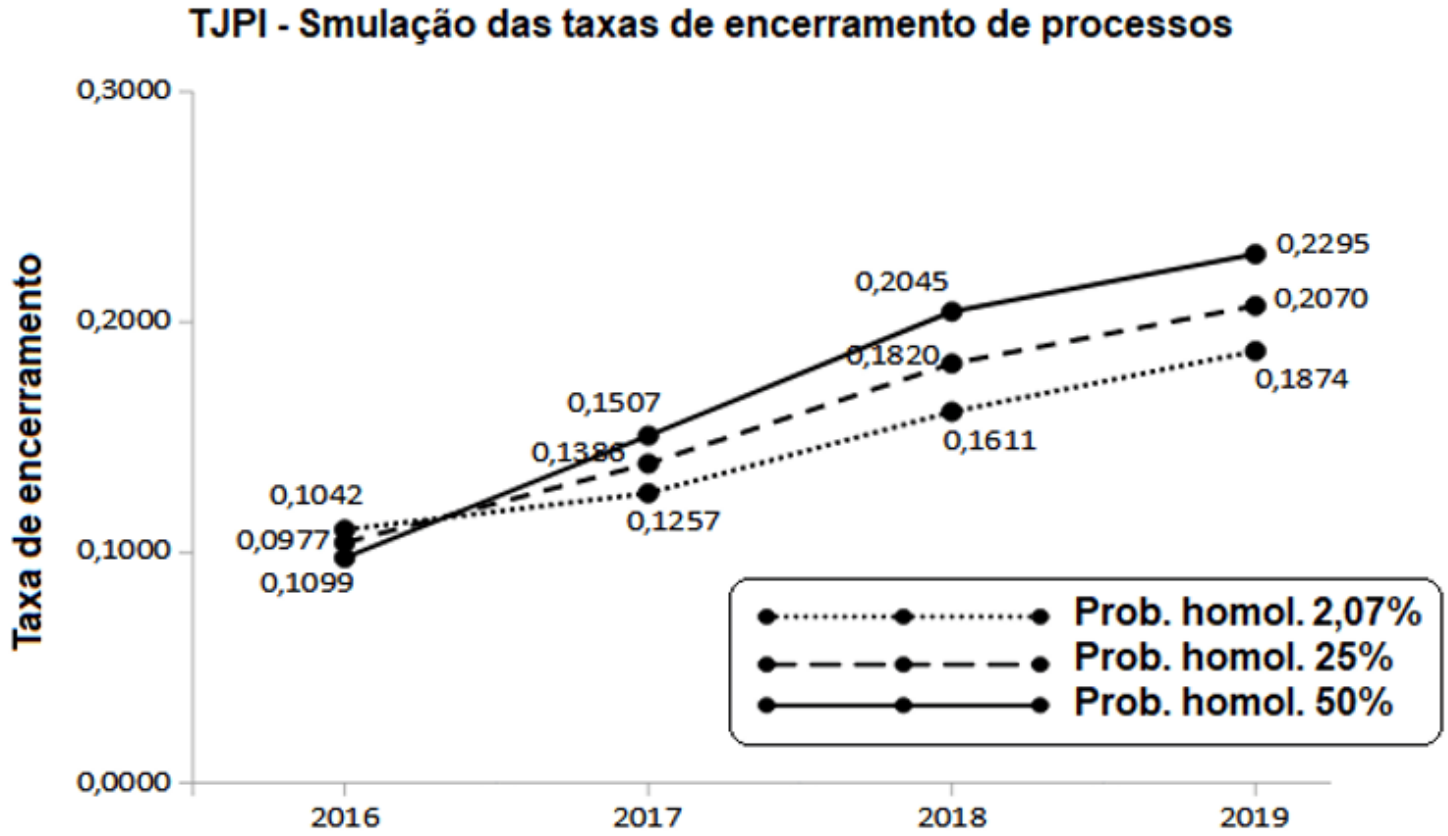

Fonte: elaborado pelos autores.

Para os dados do TJPI observa-se que após três anos (2016 a 2019) a taxa de encerramento é de aproximadamente $2 \%$ maior comparando-se proporção de homologação de $25 \%$ com a proporção estimada de 2,07\% (dados da amostra). Em 2019, de cada lote de 100 processos, seria esperado o encerramento de 20,70 processos contra o valor esperado de 18,74 processos com taxa de homologação a $2,07 \%$.

\section{RESULTADOS E DISCUSSÃO}

Os dados fundamentais para os resultados deste trabalho consistem nos valores de probabilidade de tempo de encerramento do processo (homologado e não homologado) que estão apresentados na Tabela 2. Vale ressaltar que os dados desta tabela são oriundos de uma amostra de 256.056 processos de 17 municípios,

RC: 90115

Disponível em: https://www.nucleodoconhecimento.com.br/lei/aparato-do-judiciario 
sendo cinco piauienses, oito paulistas e quatro do Rio de Janeiro conforme comentado anteriormente.

Suponha que se considere que um tempo de encerramento de um processo de até dois anos seja adequado, ou seja, seja eficiente em termos de atuação da Justiça para resolução de conflitos. Então, com base na Tabela 2, os processos homologados em São Paulo têm probabilidade de se encerrar em até dois anos de $0,43516+0,32410=0,75926 \approx 75,93 \%$. Já para os processos não homologados esta probabilidade vale $0,19311+0,17613=0,36924 \approx 36,92 \%$. Isto significa dizer que a mediação/conciliação apresenta mais chance de resolução de conflito em dois ou menos anos se comparada proporciona a redução significativa do tempo de vida do processo no âmbito da esfera judicial.

Em outras palavras, os dados da amostra de processos no âmbito do TJSP apontaram que de cada 100 casos novos de $1^{\circ}$ grau que foram homologados, 76 foram encerrados em até dois anos, enquanto que de cada 100 casos novos não homologados, apenas 37 foram encerrados neste mesmo período, o que evidencia a eficiência da mediação/conciliação pois menor tempo proporciona menor distribuição de carga de processos por magistrados e por servidores e consequentemente aumento na qualidade da avaliação de processos por parte dos mesmos, e também algum grau de redução de custos em geral para o Judiciário.

Para interpretação dos dados dos três tribunais, na Tabela 9 são apresentadas as probabilidades, chances de encerramento e raiz de processos homologados e processos não homologados em até dois anos com base nas estimativas de probabilidade de encerramento apresentadas na Tabela 2.

Tabela 9 - Probabilidade, chance (odds) e razão de chance (odds ratio) de processos homologados e não homologados em até dois anos
(A)
(B)

(C)

RC: 90115

Disponível em: https://www.nucleodoconhecimento.com.br/lei/aparato-do-judiciario 


\begin{tabular}{|l|l|l|l|l|}
\hline & & Probabilidade & Chance & Razão \\
Chance
\end{tabular}

Fonte: elaborado pelos autores.

RC: 90115

Disponível em: https://www.nucleodoconhecimento.com.br/lei/aparato-do-judiciario 
Existe uma diferença conceitual entre probabilidade e chance (em inglês, chance se traduz por odds). A chance é o resultado da divisão da probabilidade de ocorrência de determinado evento de interesse $E$ (em nosso caso $E$ representa o evento processo encerrado em até 2 anos) pela probabilidade de não ocorrência deste evento E. Na Tabela 9, na coluna (A) encontram-se estes valores.

Por exemplo, no Piauí, a chance (odds) de um processo homologado ser resolvido em até dois anos comparado à sua resolução em mais de dois anos é de 0,34632 / $0,65368=0,5298$. Como a chance é menor que a unidade, é melhor fazermos a 'leitura' do inverso: 1 / 0,5298 $=1,8875$ que significa dizer que 'no Piauí, a chance de um processo homologado terminar em mais de dois anos é 1,8875 vezes maior que a chance deste projeto terminar em até dois anos'. E ainda podemos dizer que 'no Piauí, a chance de um processo homologado terminar em mais de dois anos é $88,75 \%$ maior que a chance deste projeto terminar em até dois anos'.

Outro exemplo: Em São Paulo, a chance (odds) de um processo homologado ser resolvido em até dois anos comparado à sua resolução em mais de dois anos é de $0,75926 / 0,24074=3,1539$. Podemos então dizer que 'em São Paulo, a chance de um processo homologado terminar em até dois anos é 3,1539 vezes maior que a chance deste projeto terminar em mais de dois anos'.

Se considerarmos que a amostra de dados é, de fato representativa, então os dados sinalizam que no Piauí os processos são mais 'demorados' (mais de dois anos para resolução), sejam homologados ou não (note que no Piauí a chance de um processo não homologado se encerrar após dois anos é $1 /$ 0,3108 $=3,2175$ vezes maior do que ser encerrado em até dois anos). Já para o estado de São Paulo, um processo homologado sinaliza grandes chances de encerramento em até dois anos, o que proporciona por sua vez em melhor eficiência da Justiça em geral.

Finalmente, podemos avaliar a razão de chance (odds ratio) dos processos homologados em relação aos processos não homologados terminarem em até dois anos. A razão de chance é o resultado da divisão (razão) das chances (odds) de 
encerramento em até 2 anos dos processos homologados e processos não homologados. Conforme se observa na coluna (C) da Tabela 9, no Piauí a razão de chance de projetos homologados terminarem em até dois anos é 0,5298 / 0,3108= 1,7046 vezes maior se comparado a processos não homologados, ou seja, tem $70,46 \%$ mais chances de terminarem em dois anos.

Vemos que em São Paulo, a razão de chance é quase cinco vezes maior a favor dos processos homologados $(4,9825)$. Se os dados da amostra utilizada são realmente representativos dos estados avaliados, então São Paulo mostrou que processos homologados tem três vezes mais chance de serem resolvidos em até dois anos do que serem resolvidos em mais de dois anos. $E$ isto, pelas simulações realizadas apontam um razoável grau de eficiência, aqui neste trabalho refletido na redução da carga de processos por magistrado e por servidor e ainda mesmo uma discreta redução da taxa de encerramento ao longo do tempo.

No Rio de Janeiro também a simulação apontou um razoável ganho de eficiência, pois um processo homologado tem 1,3914 vezes mais ou $39,14 \%$ mais chances de ser resolvido em até dois anos se comparado às chances de ser resolvido em mais de dois anos. Além disso, um processo homologado no Rio de Janeiro apresentou, pela simulação 1,5995 vezes ou $59,95 \%$ mais chances de terminar em até dois anos se comparado a um processo não homologado.

E finalizando, os dados do Piauí mostraram que a tendência são os processos demorarem mais de dois anos para finalizar sejam processos homologados ou não. Mesmo assim, se forem homologados, em relação aos não homologados apresentaram maior chance de encerramento em até dois anos $(70,46 \%)$.

\section{CONCLUSÕES E RECOMENDAÇÕES}

Neste trabalho, a simulação com dados reais trabalhados com estimativas de dados também reais pôde sinalizar, ainda que de forma simples, cenários para o trabalho da Justiça englobando procedimentos de mediação/conciliação. A obtenção de mais

RC: 90115

Disponível em: https://www.nucleodoconhecimento.com.br/lei/aparato-do-judiciario 
eficiência da Justiça medida de forma simples através da dinâmica temporal da carga de processos por magistrado, por servidor, pela taxa de encerramento e pela celeridade do ciclo de vida dos processos parece sinalizar a favor destes procedimentos.

Contudo, para melhoria do processo de simulação talvez seja necessário realizar um plano de amostragem probabilístico mais robusto e mais abrangente. Por exemplo, para melhorar a simulação, seria interessante obter mais dados do ciclo de vida de cada processo (data exata de início e fim, entraves eventuais etc.) e outros dados tais como, custas do processo, trâmites entre setores acionados etc. A amostra utilizada neste trabalho foi inegavelmente relevante e de fácil acesso. Porém, talvez a representatividade desta amostra para o âmbito dos Tribunais pode não estar ideal e daí o alerta para que se realizem futuros trabalhos com planejamento amostral robusto.

De qualquer forma, podemos concluir que esta simulação realizada com dados reais sinalizou que a mediação/conciliação podem sim, contribuir proativamente para a melhoria (eficiência) do sistema Jurídico do País.

\section{REFERÊNCIAS}

ALVIM, José Eduardo Carreira. Justiça: acesso e descesso. Rio de Janeiro: EMASRF, 2003. Disponível em: Justiça: acesso e descesso - Jus.com.br | Jus Navigandi. Acesso em: 4 de jun. 2021.

BRASIL. Lei № 13.105, de 16 de março de 2015. Código de Processo Civil. 2015b. Disponível em: http://www.planalto.gov.br/ccivil_03/_Ato20152018/2015/Lei/L13105.htm. Acesso em: 10 mar. 2021.

BRASIL. Lei № 13.140, de 26 de junho de 2015. Dispõe sobre a mediação entre particulares como meio de solução de controvérsias e sobre à autocomposição de conflitos no âmbito da administração pública; altera a Lei no 9.469, de 10 de julho de

RC: 90115

Disponível em: https://www.nucleodoconhecimento.com.br/lei/aparato-do-judiciario 
1997, e o Decreto no 70.235, de 6 de março de 1972; e revoga o $\S 20$ do art. 60 da Lei no 9.469, de 10 de julho de 1997. 2015c. Disponível em: http://www.planalto.gov.br/ccivil_03/_ato2015-2018/2015/lei//13140.htm. Acesso em: 10 mar. 2019.

CONSELHO NACIONAL DE JUSTIÇA. Justiça em Números 2020. Brasília: CNJ. Disponível em: WEB-V3-Justiça-em-Números-2020-atualizado-em-25-08-2020.pdf (cnj.jus.br). Acesso em: 4 de jan. 2021.

R CORE TEAM (2019). R: A language and environment for statistical computing. R Foundation for Statistical Computing, Vienna, Austria. URL https://www.Rproject.org/.

RUTCKEVISKI, João Carlos. A democratização do acesso à justiça: uma abordagem sobre a aproximação do judiciário da realidade social. Monografia apresentada como requisito parcial à conclusão do Curso de bacharelado em Direito na Universidade Federal do Paraná, Curitiba, 2002. Disponível em: A democratização do acesso à justiça : uma abordagem sobre a aproximação do judiciário da realidade social (ufpr.br). Acesso em: 04 de jun. 2021.

Enviado: Junho, 2021.

Aprovado: Junho, 2021.

RC: 90115

Disponível em: https://www.nucleodoconhecimento.com.br/lei/aparato-do-judiciario 